\title{
On the effect of chess training on scholastic achievement
}

\author{
William M. Bart* \\ Department of Educational Psychology, University of Minnesota, MN, USA \\ *Correspondence: bartx001@umn.edu \\ Edited by: \\ Guillermo Campitelli, Edith Cowan University, Australia \\ Reviewed by: \\ Philippe Chassy, Liverpool Hope University, UK
}

Keywords: chess, cognition, education, scholastic achievement, expertise

What are the effects of chess trainingespecially on scholastic achievement among school-aged students? Can chess instruction facilitate the acquisition of scholastic competency? The current state of the research literature is that chess training tends not to provide educational benefits. This article provides a critical review of research on the effects of chess training on the scholastic achievement levels of school-aged students.

\section{EDUCATIONAL BENEFITS OF CHESS}

Various studies and conference presentations (e.g., Christiaen and Verholfstadt, 1978; Liptrap, 1998; Bart and Atherton, 2004) provided results in support of the educational benefits of chess instruction in the schools. Gobet and Campitelli (2006) reviewed that research and reached the following conclusions: (a) the educational effects of optional scholastic chess training remain undetermined; (b) compulsory scholastic chess instruction may engender motivational problems among students; and (c) chess instruction may be beneficial among novices, but is less important among intermediate and advanced players for whom the amount of practice and the acquisition of knowledge are of paramount importance. Gobet et al. (2004) contended that such conclusions are in line with the view of de Groot (1977, 1978) that educational benefits of chess instruction are likely "low-level gains" such as improvements in attention and concentration and interest in learning, rather than "high-level gains" such as improvements in intelligence, scholastic achievement, and creativity.

Additional research is supportive of de Groot's view. Bilalić et al. (2007) determined that intelligence explained a smaller amount of the variance in chess skill among competent young chess players than the amount of practice time. Waters et al. (2002) also found little support for a relationship between intelligence and chess skill.

Contrary to the results of Gobet and Campitelli (2006) that chess instruction provides very modest if any educational benefits is research that attests to the benefits of chess training. For example, Smith and Cage (2000) reported the effects of $120 \mathrm{~h}$ of chess instruction on the mathematics achievement among rural, AfricanAmerican secondary school students in northern Louisiana. They determined that the treatment group composed of 11 females and 10 males scored significantly higher in mathematics achievement and non-verbal cognitive ability than the control group composed of 10 females and 10 males after controlling for differences among pretest scores.

In a more recent study Aciego et al. (2012) used a quasi-experimental study to examine the cognitive effects of chess training. The experimental group consisted of 170 students, 6-16 years of age, who received extracurricular chess instruction. The comparison group consisted of 40 students in a similar age range. Those students received extracurricular sports (soccer or basketball) activities. The Wechsler Intelligence Scale for Children (WISC-R) and a record completed by the tutor-teacher to measure problem solving were dependent variables.

After adjusting for pretest scores, the chess group registered significantly higher posttest scores than the sports group for five of nine WISC-R subtests-i.e., the Similarities, Digit Span, Block Design, Object Assembly, and Mazes subtests. The chess group also registered significantly higher posttest scores in problem solving capacity than the sports group. The authors concluded that chess is a "valuable educational tool" (p. 558).

In another recent study Kazemi et al. (2012) examined the cognitive effects of chess play. They employed an experimental group composed of 86 randomly selected school-aged students, who received chess instruction for six months, and a control group of 94 randomly selected school-aged students. All participants were male and from 5th, 8th, and 9th grades from schools in Shanandaj in western Iran. All participants were administered a measure of metacognitive ability and a grade-appropriate mathematics exam prior to and after the intervention.

The chess group participants registered significantly higher posttest metacognitive ability scores and higher posttest mathematics test scores than the non-chess group participants. A major conclusion of the study is that chess instruction improves significantly the mathematical abilities and the metacognitive capacities of school-aged students.

In a third study, Trinchero (2013) examined the effects of chess instruction on the mathematical ability of primary school students. His study involved 568 primary school children in Italy placed in four groups: (1) experimental, (2) control, (3) experimental without a pretest, and (4) control without a pretest. The experimental group received chess training in addition to ordinary class lessons. The control group only received ordinary class lessons. One prominent result was that the experimental group that received chess training registered a modest but statistically significant increase in scores on mathematics test 
items that required problem-solving skills on complex tasks. That effect was greater among students who had more hours of chess instruction.

These last four studies lend support to the view that chess training has positive cognitive effects on regular schoolaged students. In addition, there are some studies that address the issue of cognitive effects of chess training on school-aged students with disabilities.

Scholz et al. (2008) investigated the effects of chess training on mathematics learning among students with learning disabilities based on intelligence scores in the 70-85 IQ range. School classes from four elementary schools in Germany were randomly assigned to two groups: (a) an experimental group that received chess instruction of one hour per week for one entire school year; and (b) a comparison group that received supplementary mathematics instruction of one hour per week. The two groups did significantly differ in their calculation abilities for simple addition tasks and counting. The authors concluded "chess could be a valuable learning aid for children with learning disabilities" (p. 138).

In a second study Barrett and Fish (2011) investigated the cognitive effects of a 30 -week chess-training program within mathematics classes for students in special education in a middle school in southwestern United States. All participants qualified for special education services and were in either 6th, 7th, or 8th grades. A sample of 31 participants were randomly placed into two groups: (a) an experimental group composed of 15 students who received the chess instruction along with a sizable portion of the regular instruction in resource mathematics specially designed for students in special education; and (b) a comparison group composed of 16 students who received all of the regular mathematics instruction in resource mathematics rather than any chess instruction. The dependent variables for this study were scores on the mathematics Texas Assessment of Knowledge and Skills (TAKS) that is a standardized test of mathematics competencies for pre-collegiate students in Texas, and end-of-year course grades in resource mathematics. All participants completed a version of the mathematics TAKS that was modified for special education students.

This study had some interesting results. First, there was a significant relationship between chess instruction and end-ofyear grades. Second, there was a statistically significant relationship between chess instruction and mathematics TAKS test scores.

This study provided support that chess instruction facilitates transfer of cognitive skills from chess to mathematics for students in special education.

These latter two studies using special education students indicate that chess instruction has the potential to promote mathematics achievement among students in special education.

In a third study Hong and Bart (2007) examined the cognitive effects of chess instruction on students at risk for academic failure in Korea. The total sample of participants was 38 students from three elementary schools randomly placed into two groups: (a) an experimental group that received 90-min chess lessons weekly for 3 months; and (b) a comparison group that received regular school activities after class.

All participants were tested prior to and after the intervention with the following several instruments: (a) the Test of Nonverbal Intelligence-Third Edition (TONI-3) to measure cognitive ability in a language-free manner; and (b) a Chess Skill Rating method using chess software to assess level of chess competency.

TONI-3 posttest scores and chess skill ratings were significantly correlated after controlling for TONI-3 pretest scores. This statistical finding suggests that chess instruction that produces higher chess skill ratings may lead to gains in levels of nonverbal intelligence among students at risk for academic failure.

These studies indicating positive effects of chess training among students with disabilities support the view of Storey (2000) who extolled the use of chess training as a means to promote higher-order thinking skills among disabled students. Storey (2000, p. 47) recommended that teachers consider "chess as an instructional strategy for reinforcing skills such as concentration, problem identification, problem solving, planning strategies, creativity, and lucid thinking."
But why would chess training lead to improvements in scholastic achievement? To play chess well, one must attend to and comprehend chess positions and induce patterns among the pieces, an indication of fluid intelligence and concentration capacity. The chess positions can be very complex with up to 32 pieces from six piece types arrayed on a 64 square board.

One must then formulate and evaluate possible moves, an indication of executive functioning and critical thinking. For example, middle game positions often permit 30 different legal moves at every turn. The chess player must ideally evaluate positions resulting from such moves selecting the move that produces the position most advantageous to the player. The chess player must evaluate chess moves and their resulting positions without actually moving any pieces. There are thus substantial demands on visual working memory.

In chess, one must engage in this sequence of (1) position comprehension, (2) pattern induction, and (3) move formulation and evaluation relatively quickly. This coordinated set of cognitive skills required in competent chess play likely transfers to the learning of mathematics and related fields that also often require comprehension, induction, analysis, and evaluation of complex phenomena. This constitutes a theoretical framework why chess training likely has cognitive benefits. This cognitive explanation for the benefits of chess training is compatible with comparable explanations provided by Storey (2000) and Trinchero (2013).

\section{CHESS TRAINING, EXPERTISE, AND THE ISSUE OF RESEARCH RIGOR}

The research reported thus far provides evidence that chess training has salutary cognitive and educational effects among school-aged students. However, the argument of Gobet and Campitelli (2006) needs to be considered before we can be confident that chess training is a valid means to improve scholastic achievement levels. To Gobet and Campitelli (2006), rigorous experimental research is needed to determine the extent to which chess training has strong cognitive and educational effects.

However, such rigorous experimental inquiry involving, for example, 
random placement of participants into experimental and control groups is costly and difficult to implement in a school setting. What is needed is an increase in the quality and quantity of empirical studies to determine the extent to which the acquisition of chess expertise facilitates the acquisition of scholastic expertise among students.

\section{REFERENCES}

Aciego, R., Garcia, L., and Betancourt, M. (2012). The benefits of chess for the intellectual and social-emotional enrichment in schoolchildren. Span. J. Psychol. 15, 551-559. doi: 10.5209/rev_SJOP.2012.v15.n2.38866

Barrett, D., and Fish, W. (2011). Our move: using chess to improve math achievement for students who receive special education services. Int. J. Spec. Educ. 26, 181-193.

Bart, W., and Atherton, M. (2004). "The neuroscientific basisof chess playing: applications to the development of talent and education,"in Paper Presented at the "Learning to Know the Brain Conference" (Amsterdam).

Bilalić, M., McLeod, P., and Gobet, F. (2007). Does chess need intelligence? - A study with young chess players. Intelligence 35, 457-470. doi: 10.1016/j.intell.2006.09.005

Christiaen, J., and Verholfstadt, D. C. (1978). Chess and cognitive development. Nederlandse Tydschrift voorde Psychologie en haar Grensegebieten, 36, 561-582.

de Groot, A. D. (1977). "Memorandum: Chess instruction in the school? A few arguments and counterarguments," in Chess in the Classroom. An answer to NIE, ed H. Lyman, (Saugus, MA: The Massachusetts Chess Association and the American Chess Foundation), 1-10.

de Groot, A. D. (1978). Thought and Choice in Chess. The Hague: Mouton. (Original work published in 1946).

Gobet, F., and Campitelli, G. (2006). "Education and chess: a critical review," in Chess and Education: Selected Essays from the Koltanowski Conference, ed T. Redman (Dallas, TX: Chess Program at the University of Texas at Dallas), 124-143.

Gobet, F., de Voogt, A., and Retschitzki, J. (2004). Moves in Mind: The Psychology of Board Games. New York, NY: Psychology Press.

Hong, S., and Bart, W. (2007). Cognitive effects of chess instruction on students at risk for academic failure. Int. J. Spec. Educ. 22, 89-96.

Kazemi, F., Yektayar, M., and Abad, A. M. B. (2012). "Investigation of the impact of chess play on developing meta-cognitive ability and math problem-solving power of students at different levels ofeducation," in 4th International Conference of Cognitive Science (ICCS 2011), Procedia-Social and Behavioral Sciences, Vol. 32, 372-379.

Liptrap, J. M. (1998). Chess and standard test scores. Chess Life, 41-43.

Scholz, M., Niesch, H., Steffen, O., Ernst, B., Loeffler, M., Witruk, E., et al. (2008). Impact of chess training on mathematics performance and concentration ability of children with learning disabilities. Int. J. Spec. Educ. 23, 138-156.

Smith, J. P., and Cage, B. N. (2000). The effects of chess instruction on the mathematics achievement of southern, rural, black secondary students. Res. Sch. 7, 19-26.

Storey, K. (2000). Teaching beginning chess skills to students with disabilities. Prevent. School Fail. Alter. Educ. Child. Youth 44, 45-40. doi: 10.1080/10459880009599782

Trinchero, R. (2013). Can Chess Training Improve Pisa Scores in Mathematics? An Experiment in Italian Primary School. Paris: Kasparov Chess Foundation Europe.

Waters, A. J., Gobet, F., and Leyden, G. (2002). Visuospatial abilities of chess players. Br. J. Psychol. 93, 557-565. doi: 10.1348/000712602761 381402.2002

Conflict of Interest Statement: The author declares that the research was conducted in the absence of any commercial or financial relationships that could be construed as a potential conflict of interest.

Received: 06 March 2014; accepted: 29 June 2014; published online: 08 August 2014.

Citation: Bart WM (2014) On the effect of chess training on scholastic achievement. Front. Psychol. 5:762. doi: 10.3389/fpsyg.2014.00762

This article was submitted to Cognition, a section of the journal Frontiers in Psychology.

Copyright (c) 2014 Bart. This is an open-access article distributed under the terms of the Creative Commons Attribution License (CC BY). The use, distribution or reproduction in other forums is permitted, provided the original author(s) or licensor are credited and that the original publication in this journal is cited, in accordance with accepted academic practice. No use, distribution or reproduction is permitted which does not comply with these terms. 